\title{
INFELICES EXTREMOS DE SENSIBILIDAD EN LAS LECTURAS DE OLAVIDE
}

\author{
María José ALONSO SEOANE \\ Universidad Complutense de Madrid
}

Las Lecturas útiles y entretenidas de Olavide constituyen en sí mismas un corpus muy importante de novelas que, en España y en español, ofrece una antología de diferentes géneros de novela corta, tal como puede entenderse en la segunda mitad del siglo XVIII'. Todas son de Olavide, que escribe -y bienbajo el nombre supuesto de Atanasio de Céspedes y Monroy; y todas se presentaron a censura entre 1799 y $1801^{2}$. Probablemente son todas también adaptaciones de obras francesas o de otros países a través del francés, según la práctica habitual europea de adaptación, común en la época. En cualquier caso, como ocurre con otras obras similares que se publicaron por entonces en España, lo más importante de las Lecturas -cuyo influjo fue considerable (Alonso Seoane 1985, pp. 21-22)- es su papel en la difusión de los nuevos géneros, que traían nuevas mentalidades y sensibilidades, además de los gustos y técnicas narrativas.

Olavide termina su extensa colección poco antes de su muerte (1803), siendo persona ya mayor, aunque activo y atento a toda novedad, como siempre. En ella selecciona obras muy diversas, también de diferentes épocas dentro de la común modernidad relativa al conjunto. Entre ellas se encuentran obras como Ernestine de Mme. Riccoboni (1765; $2^{\mathrm{a}}$ ed., 1790, sin variantes); Germeuil (1777) de Baculard d'Arnaud y Félix et Pauline (1794) de Pierre Blanchard (Alonso Seoane 1991, 1987, 1992, respectivamente). La intención de Olavide no parece ser la de limitarse a reunir sus abundantes experiencias de lector-de acuerdo con sus convicciones, y una vez ajustadas a los criterios de

1. Corta o no tanto, de cierta entidad; nunca en el estilo del cuento moral, de dos o tres páginas; tampoco demasiado extensa. Si son largas, muchas veces se sigue el simple procedimiento de dividirlas en dos o tres parte. No incluye novela epistolar.

2. Según el expediente conservado en el Archivo Histórico Nacional. Preciso los datos correspondientes en un estudio que espero publicar en fecha próxima. 
la colección señalados en el Prólogo $o^{3}$, sino la de dar sólo lo que en su momento pudo tener en sus manos y le pareció que valía la pena dar a conocer en España. Si no hay duda de que la novela corta había experimentado una renovación entre 1755 y 1799 (Godenne, 1970), y, dentro de ella, otra de 1780 a 1820 (Godenne, 1985b), Olavide trae a España una selección equilibrada y representativa. En principio, se advierte que, entre lo que elige, conoce y sigue algunas de las últimas tendencias que habían supuesto una evolución de la novela corta en ese período. Claro está, no recoge -no hubiera podido hacerlo- lo que vendrá inmediatamente después y caracterizará la novela gótica, en sentido estricto o amplio; y, en general, la novela propia de los años que van de 1800 a 1820, que, con el desfase correlativo, irá llegando posteriormente a España.

De la parte ilustrada-racional (tan importante) me he ocupado en otras ocasiones (Alonso Seoane 1986 y 1988b). La parte que, desde la sensibilidad e hipersensibilidad dieciochesca da al futuro, tiene también gran relevancia en las Lecturas, con elementos emocionales en que, por ejemplo, lo macabro alcanza a veces concreciones desagradables que no dejan de sorprender en la imagen conocida del ilustrado Olavide. Todo se lo va a encontrar el lector español, igualmente envasado y en los primeros años del siglo: las Lecturas constituyen la más importante colección de novelas en que pueda aficionarse al género, aprender sus fórmulas y familiarizarse con ellas, hasta ya entrado el Romanticismo. En este artículo nos centraremos en esa parte de las Lecturas en que no predomina lo claro y razonable -que siempre está en la base-, sino lo que corresponde a la esfera de la sensibilidad extremada en sus aspectos desdichados; aspectos que están relacionados con la novela negra, novela de terror o novela gótica, más cerca, como podía esperarse, a la configuración francesa del género. Con respecto a este tema y el tan importante de las relaciones y diferencias con el Romanticismo en las obras sensibles y góticas del XVIII y comienzos del XIX, no es posible hacer aquí un desarrollo amplio; pero, siendo necesario hacer algunas precisiones que están en la base de este trabajo, intentaré exponer brevemente lo esencial de mi opinión sobre el asunto.

En primer lugar, en las Lecturas útiles y entretenidas y en la novela que se publica en España en la época (en torno a 1800), el tipo de goticismo que se da es el que corresponde a la formulación francesa del género -siempre dentro de la que excluye el horror sobrenatural y religioso, y de obras que no son de verdadera perversidad gótica ni novela libertina- en la segunda mitad del siglo XVIII. Así ocurre con algunas de las novelas del género sombre de Arnaud y las que le siguen en su estilo y evolución; también, en novelas inglesas -que llegan a Francia y, en su momento, a España- que no presentan los caracteres arriba indicados, característicos de las obras capitales del género gótico. Obras

3. Lecturas morales para la juventud; siguiendo, en líneas generales, el pensamiento católico de Olavide, que también pone de manifiesto en el prólogo; y que, en los textos de las novelas, se resuelve en contra de "filósofos" y libertinos (El secretario filósofo, El matrimonio infeliz, etc.). 
que son, a su vez, "novelas con elementos góticos", por emplear palabras del importante artículo de Carnero (1993). En la colección de Olavide tampoco se llega a las truculencias que aparecen en otras obras españolas -relacionadas con extranjeras-, en principio ligeramente posteriores (lo que habría que adjudicar al todavía suficiente buen gusto de Olavide y la calidad de las novelas que recoge $)^{4}$. Lo que sí se aprecia en la narrativa publicada en la época en España, en número notable y cada vez con abundancia mayor, es la inclusión de elementos que perdurarán en la posterior novela gótica y otros que encontrarán en ella un alcance realmente específico: en ese sentido hablo cuando me refiero a elementos góticos y a lo gótico a lo largo de este artículo.

Por otra parte, en esta novela -sobre todo en cómo se da en Francia en la segunda mitad del siglo XVIII, donde, desde todos los puntos de vista, debe situarse la colección de Olavide-, confluyen las nuevas tendencias con raíces que vienen de atrás. En cierta línea de continuidad, lo que encontramos son manifestaciones dieciochescas de motivos que, aunque algunos antiquísimos y universales, en el comienzo de la Europa moderna aparecen en el relato breve italiano (Boccaccio, Giraldi, Bandello) -en la vertiente trágica, en prosa y teatro-, y derivan en las distintas naciones a través del XVII hasta introducirse en el período de la Ilustración, con las modificaciones correspondientes y en contraste con las corrientes contrarias tan características de la época. Por lo general, hay una cadena de inspiración en que se encuentran formulaciones muy parecidas de variantes de los mismos motivos -como el de seductor y seducida o el del honor conyugal herido (Frenzel 1980)-, que se desarrollan diacrónicamente y se expanden sincrónicamente también, en amplia difusión literaria en los distintos países de la cultura europea. Esto es lo que hace tan densa toda esta trama de influencias y las convierte en más complejas y relativas en cuanto a la determinación del influjo de sus motivos. Por eso considero básico partir de que, siempre, en cada obra determinada -si se trata de obras de entidad, con calidad estética-, lo esencial es el conjunto de la misma: es en ese conjunto en el que las mismas o parecidas formulaciones de uno o varios motivos -a veces, argumentos, como el de Inés de Castro-, encuentran el sentido específico que las diferencian de modo esencial de lo anterior y posterior. Particularmente, en el caso de las obras antecedentes en que pueden encontrarse los mismos motivos, con una semejanza fragmentaria que sorprende.

Desde este punto de vista, y refiriéndose a la literatura española, esto ocurre con la sensibilidad y sus situaciones en los dramas serios del siglo XVIII, sin que, en mi opinión, deba darse a unidades argumentales o motivos de obras célebres que luego reaparecen en otras obras románticas importantes a veces más de medio siglo más tarde; y teniendo en cuenta que antes y después habían pasado por una y mil reformulaciones en distintos géneros y países-

4. En lo que se refiere a España y al teatro, a veces relacionadas con el tema de los bandidos, en el teatro de la época (Palacios, 1993). Sin olvidar, una vez más, que se habían dado en épocas anteriores; en determinado tipo de novela corta y en el teatro de horror del Siglo de Oro. 
igual significado. Con ello, sólo se conseguiría hacer perder especificidad a los distintos períodos y movimientos, desdibujados en una indefinida evolución continua. Con mayor motivo, posiblemente, puede observarse lo mismo por lo que respecta a elementos de lo genuinamente gótico -también de posterioridad notable- a pesar de la exactitud del parecido de sus formulaciones en unidades concretas 5 . Lo cual no significa desconocer la importancia del proceso de transmisión de determinados motivos y sus transformaciones, así como de un determinado lenguaje, sino señalar solamente el valor relativo de las proporciones de semejanzas y diferencias, y la importancia de insistir en la determinación de la entidad básica original, en una obra o período literario.

Todo esto puede verse, en muchos casos, en relación a la novela. Así, esto ocurre con el tema de la Edad Media en el último período de la Ilustración. La Edad Media, que había estado de moda en la novela corta francesa de fines del XVII, vuelve a estarlo en la segunda mitad del siglo siguiente (Godenne, 1970; 1985b). Pero la Edad Media de la novela "troubadour" es distinta por completo, conceptualmente, a la del Romanticismo; en él, la Edad Media que se configura -a pesar de lazos y relaciones- procede directamente del sentido romántico de la historia (Schenk, 1983), cuya importancia es tan radical que transforma esencialmente el tema. Otro ejemplo sería el de la mayor sobriedad en la sensibilidad y su expresión con respecto al lenguaje y a la lacrimosidad que encontramos en las mejores obras españolas románticas, con respecto a la de las obras sentimentales del XVIII (Vincent-Buffault, 1986). Y que, en lo temático, de hecho se da en el Romanticismo (Picoche, 1985, para lo relativo a la escenografía) una propensión relativamente menor hacia lo cruel, macabro y lúgubre morboso que en algunos casos de esa misma literatura -que, en parte, puede ya considerarse gótica-, y en la propiamente gótica; dejando aparte el que las diferencias sobrepasen la relevancia de las semejanzas. Todo ello debe hacerse extensible a la literatura de horror anterior, derivada de los modelos italianos -pasando por Camus en Francia-, y lo demás del XVIII y de la literatura popular de comienzos del XIX ${ }^{6}$.

5. A veces muy apreciables y, por su importancia, deben ser tenidos en cuenta; pero no, en mi opinión, de manera que desdibujen el sentido del conjunto que da identidad a una obra o movimiento literario. No podemos extendernos aquí sobre el lema, ni analizar múltiples ejemplos de las Lecturas que establecen relaciones con obras románticas posteriores. Para todo ello remito a mi edición de La conjuración de Venecia, año de 1310 (1993). También, desde un punto de vista general, respecto al artículo de J. Herrero (1989) que no pude incluir entonces; no es posible ahora, en el espacio de que disponemos y al estar centrado el artículo no en el Romanticismo en relación a los modelos góticos antecedentes sino, prácticamente, en el aspecto contrario, entrar en un análisis detallado, por el mismo interés del tema; esperamos poder hacerlo próximamente con la atención debida, igual que con la cuestión de las relaciones de las obras románticas con las sensibles del XVIII.

6. Me refiero fundamentalmente a Agustín Pérez Zaragoza. Su colección, generalmente conocida por el título abreviado, Galería fúnebre de Espectros y Sombras Ensangrentadas, incluye - también- el más largo de Obra nueva de prodigios, acontecimientos maravillosos, apariciones nocturnas, sueños espantosos, delitos misteriosos, fenómenos terribles, crimenes históricos y fabulosos, cadáveres ambulantes, cabezas ensangrentadas, venganzas atroces y casos sorprendentes, que corresponde al de la obra de P. [J.P.R.] Cuisin, Les Ombres Sanglantes, galeries funèbres de prodiges, événements merveilleux, apparitions nocturnes, songes épouvantables, délits mystérieux, phénomènes terribles, forfaits historiques, cadavres mobiles, têtes ensanglantées et 


\section{CONTEXTO EN ESPAÑA}

Evidentemente, lo que ofrece Olavide no es una excepción entre lo que era conocido por entonces en España. Tenerlo en cuenta no quita interés a las Lecturas, sino que las sitúa en un contexto en que determinados gustos se preparan, y después determinadas obras siguen el camino abierto. No podemos entrar aquí en la cuestión, que siempre hay que tener presente, de las relaciones de la novela con las demás expresiones literarias de la época; muy especialmente, con el teatro (Alonso Seoane, 1994), aunque aún no habían llegado las exarcerbaciones de comienzos del XIX a la escena. Al menos, en lo que se refiere a la narrativa, que es el contexto genéricamente inmediato a las Lecturas, intentaremos dar una visión de conjunto de las obras más significativas ${ }^{7}$, asequibles a los lectores ( $y$ a los lectores-autores) españoles de finales de la Ilustración. Evidentemente, hay que tener en cuenta que, además de lo traducido -por lo general de forma adaptada, se advierta o no-, muchas obras extranjeras eran conocidas por algunos en otros idiomas; francés, por lo general. Su cuantificación es imposible, aunque tenemos múltiples rastros: por ejemplo, las novelas que se dramatizan y las presentadas a censura que no consiguieron el permiso de impresión. También, la crítica en prensa cuando, en alguna ocasión, redactores bien informados exponen sus teorías y demuestran estar al tanto -al menos en cuanto a su existencia-de obras recientes en sus países de origen $^{8}$.

Con respecto a las novelas -modernas entonces- con elementos góticos que se publican en los diez años anteriores a la edición de las Lecturas, aproximadamente, y hasta la guerra de la Independencia -por tratar sólo las más próximas a

animées, vengeances atroces et combinaisons de crimes, etc., puisés dans des sources réelles. Recueil propre à causer les fortes émotions de la terreur, 2 vols., Paris, Vve. Lepetit, 1820 (Lévy 1968, pág. 513). El eco de la última parte del título de Cuisin aparece al final de la "Introducción analítica" de la colección (Cuenca, 1977, pág. 65). Una prueba añadida de la dependencia de este tipo de literatura con los modelos italianos es la historia de la condesa de Amalfi, que se incluye, y que ya aparece en Bandello-como anota Cuenca, con algunas formulaciones posteriores (1977, pág. 203). Como dato curioso, por esas fechas se publica La princesa de Amalfi (París, David, 1830), "Por el Conde Fedor Golowkin; traducido al español por la señora Hermancia de Ayala". Con respecto a esto, tiene interés la transmisión francesa de los temas de Bandello en España y el carácter de los mismos (Arredondo, 1989a y 1989b); el papel especial de Camus en Francia, que se introduce en el siglo XVIII (Godenne 1985a).

7. Algunas señaladas (Carnero, 1985; Glendinning, 1994).

8. Es el caso de la reseña que publicó el Memorial Literario con motivo de la traducción de Oderay, por Zavala y Zamora. En ella, traido tangencialmente a propósito de la proliferación de obras desenfienadas después de algunas importantes que marcan la imposición de un género, se muestra el avance de la sensibilidad gótica, en concreto en la novela: "Cuando Madama Radcliffe publicó los Misterios de Udolfo y el Italiano o el Confesionario de los Negros, y Madama la Roche Los Niños de la Abadía, la Inglaterra se vio inundada de novelas: las que, queriendo imitar a aquellas, solo fueron una serie de embrollos y de disparates los más absurdos; sean ejemplo $E$ l Conde de Santerre, El espiritu de Turretwille o La semejanza misteriosa, y otras varias" (M[ariano] C[arnerero] 1805, pág. 166). Ha llamado mi atención hacia esta reseña Carlota del Amo Cabezas que, bajo mi dirección realiza actualmente una tesis sobre novela y prensa en España en el primer tercio del siglo XIX, dentro de esa línea de investigación que considero de gran interés, en los trabajos de que me ocupo sobre la novela de la época. C $-:$ respecto a los textos que cito, modernizo ortografía y puntuación, manteniendo los nombres propios y títulos tal como aparecen. En las citas de obras de Olavide se indica sólo tomo y página. 
las de Olavide" -, aparece un número apreciable de obras, españolas y extranjeras, contando sólo con las que se imprimen en España y estaban, por tanto, en principio, a disposición de quien desease leerlas ${ }^{10}$. Las inclusiones pueden ser discutibles: no siempre los elementos aludidos se presentan claros o con bastante extensión, pero son significativos como entorno de las Lecturas, estudiadas en los mismos aspectos. No dejan de notarse los años más afectados por las reticencias del Consejo en contra de la publicación de novelas; así como se ve, a medida que avanzan las fechas, cómo se va animando el gusto hacia estos temas. Recogemos sólo la primera edición en las fechas acotadas, deteniéndonos apenas para dar ejemplos, en alguna de las obras españolas.

1787-1792. Voz de la naturaleza de Ignacio García Malo. Fundamentalmente, en sus anécdotas Lisandro y Rosaura, El celoso indiscreto, El ViceMariscal y Carlota, El sensual por sistema y padre criminal desengañado" ${ }^{\text {. }}$

1790. Fray Vicente Martínez Colomer, Nueva colección de novelas ejemplares.

1791. Bernardo $\mathrm{M}^{\mathrm{a}}$ de Calzada, La verdadera historia de Inés de Castro, suceso portugués ${ }^{12}$.

1792. Los dos Robinsones o Aventuras de Carlos y Fanny, dos niños ingleses abandonados en una isla desierta de América, por D. Justo de la Barra (el original es de Ducray-Duminil). El Valdemaro de Martínez Colomer. El café, obra muy curiosa - tan de la época en que, en el café, se habla y se maneja la prensa, "Por D. Alejandro de Moya". En esta obra se manejan argumentos de novelas y relatos que se orientan al género negro o de terror. Así sale el caso del Abad de Rancé, el de la Princesa casada con el bárbaro "Czarowitz, hijo del

9. Con lass que presentan otras coincidencias de interés, aunque también debamos renunciar a entrar ahora en ello.

10. Con este criterio, no incluyo obras a las que se negó licencia de impresión, ni otras, como Cornelia Bororquia, publicadas en el extranjero. Tampoco se tiene ahora en cuenta reediciones de novelas cortas del siglo anterior (Fernández Insuela, 1992). No anoto, salvo excepción, que la traducción de obras inglesas está hecha a través de las versiones francesas. Manejo como fuentes fundamentalmente - a las que me remito para completar los datos de las ediciones, mientras no exprese otra cosa- la obra de Montesinos (1972), importantísima, pero en la que hay que retrotraer fechas de traducciones y completar en autores y obras; Demerson (1976) -los textos de los anuncios son tan sugestivos como despistantes a este propósito; pero los datos, del mayor interés; la imprescindible Bibliografía de Aguilar Piñal (1981), en curso de publicación; así como mi propia documentación sobre el tema. Resulta de gran utilidad, en su conjunto, la obra de Álvarez Barrientos (1991).

11. En 1789-90, se publican, en el Correo de Madrid, las Noches lúgubres de Cadalso -del que también es interesante al respecto la relación con Jovellanos (Dowling 1984). En el mismo año, 1789, las Obras selectas de Eduardo Young, "expurgadas de todo error", traducidas del inglés por Don Juan de Escoiquiz.

12. Agnès de Castro, nouvelle portugaise, de Brilhac (1688, con varias reediciones en el siglo XVIII), fue traducida al inglés por Mrs. Behn (1688, The History of Agnès de Castro). Esta traducción inglesa fue a su vez traducida al francés por Thiroux d'Arconville (1761, Romans traduits de l'Anglois) (Godenne, 1970). Siendo tema tan antiguo, puede ser considerado, a la vez, indicio de nuevos gustos y Mme. de Genlis lo tratará posteriormente (1817, subtitulando su obra como Nouvelle historique). 
Czar Pedro el Grande" y el relato sobre la joven Estela, que los supera absolutamente en el terreno de lo gótico:

En su camino halla la iglesia de la aldea, situada en un paraje solitario y tenebroso; atraviesa el cementerio [...]. La escasa luz de una lámpara, que parecía alumbrar por intervalos, le deja distinguir, en medio de las espantosas sombras, los esqueletos, los huesos carcomidos, colocados sobre las frías losas. El espantoso pájaro de la noche recorre con tardo vuelo tan melancólica morada, asusta y espanta a la tímida pastorcilla con su lúgubre graznido. Entonces le parece ver una sombra que sale de entre los sepulcros, la sigue y le dice con moribunda voz: A Dios. No puede resistir más, se asusta, se espanta, se le eriza el cabello, se estremece y cae despavorida sobre un montón de huesos, que con el golpe se desunen y ruedan largo trecho. Los lentos sonidos de la campana que toca anunciando la muerte de Isidoro, acaban de oprimir su afligido corazón [...]. Llega a la puerta, halla a su madre que le aguarda impaciente [...]. Estela la mira ya con ojos moribundos (Moya, 1792, pp. 150-152).

1794. Historia de Clarisa o Clarisa Harlowe de Richarson (en 1794-95 se publica, del mismo, Pamela Andrews).

1795. En la Gaceta del 16 de Enero de 1795 se anuncia que se está imprimiendo el primer tomo de El subterráneo o la Matilde, de Miss Sophie Lee.

1795-96. Historia de Amelia Booth de H. Fielding. Empiezan a anunciarse en la Gaceta los Experimentos de sensibilidad de Arnaud; del mismo, en Barcelona, Pruebas del sentimiento, traducido por D. Francisco Ortiz de la Riba. Martínez Colomer, El impio por vanidad.

1796. Saint-Lambert, Colección de cuentos morales americanos y orientales.

1796-97. Pedro María Olive, Noches de invierno, introduce relatos con elementos de este tipo; algunos -supongo que con gran entusiasmo suyofrancamente desagradables. En principio, pertenecen a traducciones, como suele indicar. Así, La Marquesa de Ganges, que es una "causa célebre", El hijo inhumano o el delito castigado por si mismo. Historia verdadera (y conocida); o la narración del tema de Fayel, tragedia del famoso, admirable, etc. Arnaud ${ }^{13}$. Sobre todo en la novela que traduce del mismo Arnaud, Daminville ${ }^{14}$, que ocupa espacios diversos en distintos tomos, y de la que Olive hace asegurar al narrador:

Cada vez se hace más interesante la historia de Daminville; el autor ha reunido ahora todas las circunstancias más horrorosas y terribles; nos hace temblar a cada paso; se siguen unos a otros los cuadros más espantosos; se reúnen para arrancarnos lágrimas. ¿Quién no siente el mayor interés por el infeliz Daminville? ¿Quién notaría el curso de las horas, oyendo tan lamentable historia? (Olive, 1796-97, V, pág. 390).

13. Aunque se parece poco al original, recoge el horroroso asunto del marido celoso que hace comer a su mujer el corazón del amante, que aparece en la novela corta italiana, como nueva formulación de la inmediata medieval del que deriva (Frenzel, 1980, pág. 167). Godenne (1985b) considera la inclusión de este asunto en los autores que lo tratan entre 1780 y 1820 como signo de las nuevas tendencias -conscientes de la tradición. Cabe añadir que el motivo aparece también antes y después de estas fechas, dentro del ámbito de evir iipo de obras.

14. Obra que se había publicado ya en España, en el t. VII de los Experimentos de la sensibilidad (1798). 
Un tema relacionado, tratado con mucho interés en la época, es el de los negros esclavos y la inhumanidad de los europeos. Olive incluye, sobre este tema, una nota estremecedora sacada de Espíritu de los mejores diarios ${ }^{15}$.

1797. La huerfanita inglesa o Historia de Carlota Summers [Sarah Fielding], imitada del inglés por Mr. de la Place. E. Helme, Luisa o la cabaña en el valle, anunciada en la Gaceta del 28 de Julio de 1797.

1798-1807, La Leandra de Valladares de Sotomayor, en algunas de las novelas incluidas: Eduardo y Camilo, la Historia de Doña Brigida, la de Don Casimiro, la Historia de Isabela. Olavide publica El Evangelio en triunfo. 1798-99. Se anuncian, editadas en Madrid, las Recreaciones o desahogos del hombre sensible de Baculard d'Arnaud. Ducray-Duminil, Alexo o la casita en los bosques. Saint-Pierre, Pablo y Virginia: "Su lectura arranca lágrimas", dice el anuncio de la Gaceta, 19 de Febrero de 1799. La obra de Saint-Pierre tiene algunas relaciones interesantes con Félix et Pauline de Blanchard, traducida después -independientemente- por Olavide ${ }^{16}$, Rodríguez de Arellano y Polo del Águila. Se publica $L a$ noche entretenida ${ }^{17}$, con elementos de este tipo en alguna de las novelas que incluye: El solitario de los Ardennes ${ }^{18}$, novela francesa; Morton y Susana, novela inglesa; Alfonso y Feliciana, novela española. Morton y Susana, tiene numerosos elementos góticos, con tirano, víctimas, prisión, muerte, etc.

1799. Florián: Novelas, adaptadas por Zavala y Zamora.

1800. Olavide, Lecturas útiles y entretenidas.

1803. Antonio Marqués y Espejo, Memorias de Blanca Capello ${ }^{19}$ (del mismo, se publica en ese año su traducción de Mathilde de Mme. Cottin). Las tardes de la Granja o Las lecciones del Padre, traducidas libremente por Rodríguez de Arellano, en alguna de sus anécdotas ${ }^{20}$.

15. Termina la nota: "Los lectores que quieran contemplar aún más sobre tan horrorosas escenas, pueden leer la novelita de Mr. de St. Lambert intitulada El Zimeo, que acaba de publicarse, traducida al castellano" (Olive, 1796-97, V, pág. 275). Hay otros ejemplos en las Noches: la Noble y heroica venganza y otras historias con elementos de terror, casos expresamente horrorosos y crueles, de castigos y asuntos similares.

16. Olavide lo adapta como El fruto de la ambición, en las Lecturas. El título no tiene nada que ver con el original Félix et Pauline ou le tombeau au pied du Mont-Jura, que Arellano conservará en parte; en él, Olavide da señal al lector de la lección tan cara que se desprende: la ambición destruye toda felicidad en los seres más queridos.

17. De D.J.M.H.; pero, en la Gaceta, se anuncia como de D. Juan Idarroc (Juan Corradi, que algunos consideran seudónimo de Tomás de Iriarte).

18. Brunet de Baines publica Le solitaire des Ardennes en 1769 (Le passetems, Londres-París, 1769, 2 ts.).

19. Meisnner publica su Bianka Capello en 1785 , de la que hay dos traducciones francesas de 1790. En España, la obra de Marqués y Espejo se anuncia como "Obra nueva y original"; probablemente, también, considerada como obra histórica-lo que no es determinante en la épocapor la reelaboración de las fuentes que el autor emplea. Aunque es traductor-adaptador conocido, en una obra, por lo menos, parece mostrarse como autor original -aunque, pienso, siempre inspirado en narraciones ajenas-: la anécdota Anastasia o La recompensa de la hospitalidad (Madrid, 1818); relato que tiene todos los caracteres de lo ficticio, pero en el que insiste en su carácter de suceso verídico-histórico. En la edición de Valencia, 1826, se la califica de "novela original", cuya "propiedad absoluta" reclama D. Ildefonso Mompié. 
1804. Una obra propia del género: El castillo negro o los trabajos de la joven Ofelia de Anne Mérard de Saint-Just, marquesa de Ortinmar. Mis pasatiempos de Trigueros, en algunos aspectos (por lo demás, poco predominantes: Adelayda, y algún elemento de El náufrago esclavo). 1804-5. Baculard d'Arnaud, Lorimón o el hombre según es.

1805. Gaspar Zavala y Zamora, La Eumenia o La madrileña. Vicente Rodríguez de Arellano publica El Decamerón español, con algunas novelas de este tipo-también correspondientes a la moda "troubadour"21 - , particularmente, El sepulcro en el monte, adaptación de Félix et Pauline de Blanchard (Alonso Seoane, 1988a).

1806. Félix y Paulina, traducción -ésta, declarada- de la obra de Blanchard. Historia familiar de unos ilustres ingleses; Etelvina o historia de la Baronesa de Castle Acre.

1807. Adriana o Historia de la Marquesa de Brianville. L. Helme: Alberto o El desierto de Strathnavern.

1808. Una de las obras primeras consideradas del género: Los niños de la Abadía de Regina María Roche. L. Brayer de Saint-León, Maclovia y Federico o Las minas del Tirol. Olive publica en esa fecha Las dos Emilias o Los efectos del odio y de la venganza ${ }^{22}$ y William Cavendish o Los malos efectos del divorcio y del juego.

\section{INFELICIDAD Y HORROR EN LAS LECTURAS}

Como ya apuntamos, Olavide incluye en su colección algunas de las últimas tendencias de la novela corta en Europa; no necesariamente todos los tipo y autores del momento, quizá por tener en cuenta traducciones recientes, ya hechas -aparte de sus propios criterios sobre la novela y su forma de pensar. Lo no razonable y extremadamente sensible, en su vertiente oscura, aparece en distintas formulaciones en las Lecturas útiles y entretenidas, correspondiendo a las distintas ascendencias que confluyen, en la etapa final de la Ilustración, con el tipo de goticismo al que arriba nos referimos. Obras que incluyen elementos relacionados con la tradición europea de historias trágicas, con sus derivacione ${ }^{23}$ que, con la atracción de lo que se estaba haciendo en Inglaterra, constituirá lo específicamente nuevo y relacionado directamente con lo gótico

20. De Dorat, muy relacionado con el tema, aparece la traducción de la Carta del conde de Cominges a su madre, Madrid, Repullés, 1803.

21. Especialmente, La pérfida, que es una adaptación de Henriette et Luci de L. d'Ussieux. De Ussieux también es Clémence d'Entragues ou Le siège d'Aubigny, adaptada como La heroína francesa; de Mme. Riccoboni, Histoire d'Enguerrand, con el título de La selva de Ardennes (García Garrosa, 1991) y la Histoire de Christine de Souabe et de Sigefioid (adaptada como Cristina de Suabia o una mujer como ninguna).

22. En 1800 aparece Les deux Emilies, traducción de la obra de H. Lee.

23. Olavide habla de seguir el ejemplo de Camus en el Prólogo; pero, en este caso, no se refiere más que a la intención moralizante al crear una colección de novelas. No son las suyas de su estilo, aunque le lleguen ecos mezclados en esa tradición a la que me refiero. 
en sentido restringido, dentro de este tipo de obras. Sólo en un caso, entre las novelas de las Lecturas-El matrimonio infeliz-puede hablarse propiamente de novela gótica, con las salvedades a que hemos hecho referencia. Las demás son novelas con elementos góticos, considerados estos elementos con mayor o menor amplitud de concepto. Ya es significativo el hecho de que el predominio de la sensibilidad, aunque pueda en algún caso (La familia feliz) ofrecer un balance dichoso, aparece ante el lector, en el conjunto de las Lecturas, como fuente de desgracia. Sin embargo, la sensibilidad en sí misma no es causa directa de desgracia sino al contrario: en algunos casos, la dureza de unos produce la desdicha $y$, con frecuencia, la muerte de otros, que son a veces seres queridos.

En este extenso campo de lo no razonable, en su vertiente extremada -por acotar negativamente el tipo de novela o de sus elementos a los que nos referimos aquí-, los aspectos desdichados se encuentran en atmósferas muy diferentes: casos trágicos, obras del género sombre, novelas derivadas de los libros de aventuras bizantinas, novelas procedentes de ámbitos cercanos a Rousseau, novela "troubadour"... Siempre con lágrimas, pasiones, sentimientos exacerbados, heridas y muertes violentas, aflicciones no comunes, cuadros plásticos, lenguaje exaltado, dramatismo, etc. De todos ellos, hemos elegido para exponerlos aquí los elementos góticos de terror y horror, sangre, desgracias, tiranos, persecuciones de mujeres indefensas e ingredientes por el estilo, que, como apuntábamos -excluyendo el horror sobrenatural y religioso-serán, cuando se desarrolle el género, elementos imprescindibles del mismo. Antes haremos un breve balance de las proporciones en que se encuentran en el conjunto de las Lecturas lo razonable y lo sensible -por resumir en dos los aspectos principales, contradictorios y complementarios.

Hay muchas novelas de las Lecturas en que no existen elementos relacionados con lo gótico, salvo algunos que perdurarán, modificados, en las obras góticas, como las lágrimas y la sensibilidad en general. También motivos argumentales que pueden tener alguna relación, como ocurre con el recurso al duelo, orfandad, ruina, procesos penales, etc. -con todo lo que dan de sí-, muy extendidos en determinados géneros de novela y teatro de la Ilustración. En principio, no hay nada que no sea racional, plenamente ilustrado y dieciochesco en su cara amable - todo lo más, en algún caso, algo pesadamente didáctica-, en El desafio, La paisana virtuoso, La dulce venganza, Los dos amigos, El amor desinteresado, El inconstante corregido. En El Estudiante y La madre prudente, aunque el conjunto es razonable, se dan elementos góticos; en El Estudiante, como veremos, se incluye un pequeño relato de ese tipo, hacia el final de la obra, apenas integrado en la narración principal. En La madre prudente se da un caso de simulación de muerte para evitar un matrimonio; pero, a pesar del tema, no con aspectos góticos, sino lo contrario dentro de lo posible. La familia feliz, de tipo idílico, se mantiene en conjunto al margen de lo sombrío, pero incluye un pequeño episodio de persecución tiránica de joven honrada y familia, que se resuelve rápidamente del modo más favorable. En Los gemelos, una de las dos novelas de la colección relacionadas con los libros de aventuras 
bizantinas, se encuentran restos de los constituyentes esenciales del género; restos también de lo que aún sucedía en la realidad -naufragios y cautiverios, en concreto, en el ámbito mediterráneo-, y que en alguna otra novela, como $L a$ mendiga honrada, aparecen de forma fragmentaria. En Los gemelos todo se resuelve felizmente. Por el contrario, en La hermosa malagueña, de tipo similar, las desgracias acaban con los protagonistas, después de traiciones y equívocos que provocan terror y sufrimientos en abundancia.

Varias novelas de las Lecturas son declaradamente oscuras o sombrías, como La satisfacción generosa, La presumida orgullosa, La feliz desgracia y El secretario filósofo; en ellas, al termino del relato, sólo una cierta satisfacción moral redime lo pasado terrible, con crímenes y horror. Otras son totalmente desdichadas, como El matrimonio infeliz. En un ámbito sentimental e idílico, alejado de los anteriores pero con notables elementos que la acercan al terror, se encuadra El fruto de la ambición. Por último, aparecen algunas novelas en que la virtud se premia como es debido y la justicia se restablece, pero después de pasar por dificultades que contienen aspectos góticos, o muy aproximados: La mendiga honrada, La huérfana, Los peligros de Madrid, El sol de Sevilla. Si el final feliz o trágico -como pienso- resulta definitivo en el enjuiciamiento de una obra literaria, quince novelas, de las veintidós de las Lecturas útiles y entretenidas, son afortunadas en conjunto -con los matices expuestos- y tienen final feliz. En otras dos, que no contarían entre las anteriores - La satisfacción generosa y La feliz desgracia-el teórico buen bien lo es sólo de manera relativa. Tanto que, en su conjunto, no son novelas felices, ni siquiera novelas que después de desgracias múltiples acaban manifiestamente bien, y todo se olvida o sirve de gozo, como mal superado. Cinco novelas terminan mal, de tejas abajo; alguna, pésimamente: El matrimonio infeliz ${ }^{24}$.

El análisis de los elementos góticos de estas novelas puede enfocarse desde distintos puntos de vista. Así, además de los motivos argumentales, puede observarse, con el hilo central de la exaltación que proviene de las pasiones, la delirante expresión verbal de su conmoción emotiva, que verdaderamente presenta un lenguaje gótico (Gies, 1988; Caldera, 1991), y las manifestaciones psicosomáticas de las mismas: su expresión no verbal, también en lo gestual. Su relación con el teatro de la época es evidente: escenas dramáticas -desaforadas- que se narrativizan, en su expresión verbal y en el movimiento escénico de los personajes y demás extremos incluidos normalmente en acotaciones; o, si se prefiere, fragmentos de relato concebidos teatralmente -como defendía Arnaud-, que podrían directamente escenificarse. En ocasiones culminan en verdaderos cuadros plásticos, propios del drama serio (y de la pintura de la época, del tipo de Greuze). Como era de esperar, escenas y tableaux de felicidad inmensa existen también en las Lecturas; aquí nos ocuparemos de las

24. Claro está, en toda hay mal y bien, moralización o enseñanza; pero en proporciones diversas: predominante en casi todas, muy escasa (irrelevante) y -en expresión coloquial-- traída por los pelos en algunas - por otra parte, de muy distintas tendencias entre sí, como El amor desinteresado, El sol de Sevilla. 
que -tristemente- expresan desdichas. Por otra parte, la plasticidad invade lo puramente verbal en imágenes figurativas, y la plasmación de conjuntos y detalles del más puro gusto (mal gusto): concreciones gráficas macabras, sangre, miembros convulsos, etc. Claro que todo se da mezclado, normalmente -aparte de la simple exacerbación de la sensibilidad: lenguaje exaltado, lágrimas, gemidos, desmayos, temblores, gritos de horror, sangre, hechos aflictivos, etc.; lo que se reflejará, en ocasiones, en los ejemplos que expondremos.

En cualquier caso, como apuntábamos, incluso así es imposible tratarlo todo ahora extensamente ${ }^{25}$, por lo que nos limitaremos a tratar sólo lo que corresponde al motivo de la mujer afligida, violentada y aterrorizada, con sus aspectos concomitantes; la escenografía terrorífica, arquitectónica o no, y la elección, para su plasmación detenida, de detalles de tipo macabro y sangriento, incluida la extraordinaria transformación física de los personajes debida a distintos tipos de sufrimientos morales.

\section{MUJERES PERSEGUIDAS}

El motivo de la mujer perseguida e indefensa aparece con distintas formulaciones -algunas no propiamente góticas- en varias novelas. En esas historias, jóvenes desvalidas están a punto de caer en manos de libertinos, aunque, como merece su virtuosa resistencia, nada consigan. Pero, aunque no se consuma la infamia, las descripciones son vívidas. Así, en La huérfana (denunciada por el Memorial Literario) ${ }^{26}$, en que una falsa madre pretende casar a la que era tenida por su hija, que se resiste como puede, con un viejo degenerado ${ }^{27}$. La presión sobre la protagonista es tan fuerte que acaba por ceder y consiente en casarse. El viejo es cruel y físicamente repugnante; pero, además, se trata de un libertino que horroriza a la joven -lo que, en definitiva, la salva. En La mendiga honrada, Anastasia, otra madre supuesta, intenta, en este caso, vender a Peregrina. Ninguna compasión despierta en aquélla la desesperada oposición de la joven, que conmueve al que la iba a perder; pero su entrada en la habitación-trampa, donde la había encerrado, sirve para que la novela narrativice un cuadro escénico del efecto correspondiente:

[Anastasia] encuentra a su hija en medio de la pieza; inundada en su llanto y puesta de rodilla se cubría la cara con las manos, y al Marqués, que en pie y cerca de ella, la miraba estático y afligido. Este espectáculo hubiera consternado el corazón al más bárbaro. Pero aquella mujer, insensible a todo lo que no era de su interés, no pensó más que en llegarse a ella y decirle con mucha cólera: ¿Quieres perdernos? Tú das

25. Esperamos hacerio en el estudio de conjunto que preparamos sobre las Lecturas.

26. En su reseña sobre las Lecturas (Memorial Literario, I, 1801, pág. 65). Realmente, no se sabe cómo -salvo, quizá, porque se trata de Olavide- dejó pasar la censura una obra con textos tan explícitos sobre pormenores de conducta y otros aspectos de lo libertino.

27. Con elementos que siguen la idea del motivo literario de que el matrimonio niña-viejo se hace pensando en infidelidades posteriores, aparte de la esperanza de que el marido muera pronto. Aunque en este caso, el peligro es conjurado por la decencia de la niña, que se niega a casarse y sólo después accede, aunque el matrimonio no llegue a realizarse, por un mal entendido concepto de gratitud. 
unos gritos que los vecinos los oirán. La pobre Peregrina, viendo que su madre, en vez de ayudarle era el artífice de su perdición, redobla sus gemidos y se inclina a la tierra pegando su rostro contra el suelo (II, pp. 50-51) ${ }^{28}$.

En El estudiante se cuenta la historia de Margarita, huérfana y ocasionalmente sola, hermana de Ramón, protagonista de la novela. El libertino Don Fadrique la ve casualmente y "le pareció objeto digno de sus placeres" (VII, pág. 225). Intenta seducirla, y después la rapta, sin conseguir nada; por último, la joven logra escapar a través de un agujero en el muro de su encierro. Todavía le queda completar la huida, porque, después de dar gracias a Dios, recapacita: "Al instante que mi tirano se aperciba de mi fuga, correrá tras de mí por todas partes" (VII, pág. 243). Cuando ya se decide por una dirección, "empieza a correr con un movimiento tan rápido, que presto ya no podía sufrir la fatiga, pero el temor de ser cogida le daba fuerza y le ponía alas en los pies. En efecto, la infeliz muchacha corrió cuanto pudo [...] salvando zanjas y saltando vallados; hasta que, no pudiendo más, porque había comido muy poco en su prisión y menos dormido, se sintió sin aliento" (VII, pp. 243-244).

Todo se resuelve felizmente: pasa un coche con dos caballeros, que resultan ser el conde de Salmerón y su hijo Jacinto, de quien Ramón era algo así como preceptor en calidad de compañero, y la salvan. A pesar de la pobreza de Margarita, pero con un nacimiento que, según piensa su hermano, "no podía deshonrar a nadie" -pobre, pero honrada, efectivamente-, se casará poco después con Jacinto, enamorado de ella.

Sólo en El matrimonio infeliz ${ }^{29}$ el maligno poderoso consigue sus fines. Intenta comprar a Sabina, ofreciéndole dejar en libertad a su esposo, encarcelado, si se le entrega:

Sabina se horroriza [...] pero procura disimular el temblor con se estremece y el horror que le causa [...]. Con atrevida mano quiso profanar encantos que el honor hubiera respetado; pero ella rechazó sus osadías con firmeza serena (VI, pp. 244-245)

El "bárbaro", al final, consigue sus propósitos mediante un engaño. A pesar de que, en efecto, pone en libertad al esposo, Sabina -inevitablementeno sobrevive a su involuntaria deshonra (y a los miles de males y desgracias que le ocurren en toda la novela).

28. Por otra parte, las marcas físicas del libertinaje se ponen de manifiesto. En La huérfana, se describen con todo asqueroso detalle los efectos de las enfermedades originadas en el vicio (II, 7879 y passim); lo que la pobre Ventura tuvo que soportar sólo con su cercanía. Menos brutalmente aparece un tipo similar en La hermosa malagueña; en este caso, joven. De paso se critica, muy en la línea de Jovellanos, el majismo (IV, 9-10).

29. Es novela francamente negra, que presenta punto de contacto con Morton y Susana, de La noche entretenida. Pero, cmo vimos repetidas veces, motivos y argumentos-intercambiables-, con desgracias que acosan a los protagonistas, tiranos, deshonras, cárceles y muertes son frecuentes en novelas de la época. 


\section{LUGARES ESPANTOSOS}

Lo terrorífico arquitectónico, con lugares oscuros, amenazantes, espantosos de por sí, se da en la parte final de El matrimonio infeliz, cuando Sabina debe acudir varias veces a la cárcel ${ }^{30}$. Con esta oportunidad se describe repetidas veces en su interior, con las oportunas notas detenidamente expuestas:

[Sabina] atraviesa las tristes habitaciones, cuyas paredes denegridas y oscuras han oído tantos y tan tristes gemidos de los innumerables infelices que albergaron en su recinto pavoroso. Sus delicados oídos se sientes lastimados con el lúgubre ruido de las cadenas, y con el sordo rumor de los lamentos; sus pies con pasos tardos marchaban torpes, y a cada movimiento su corazón se helaba de horror. Después baja a los calabozos oscuros, más horribles que los sepulcros de los muertos. Entra en esas habitaciones del dolor, a que la luz no alcanza, donde el hombre se encuentra sepultado en un aire grosero, que nunca se ventila, y donde sólo vive para sentir que sufre. El sol no existe para estos infelices, y el pálido terror arroja de su seno hasta la idea del consuelo (VI, pp. 258-259).

Sabina se desconsuela por la situación de su esposo -se insiste en el carácter sepulcral del calabozo, que constituye el mayor tormento del alma y de los sentidos:

¿Cómo te han podido arrancar con violencia de los brazos que te adoraban para sepultarte en estas tumbas que atormentan a todos los sentidos? En estas negras y funestas bóvedas, en estos muros húmedos y fríos te tienen encerrado con todos los fantasmas que produce el terror (VI, pág. 259).

Con sentido teatral, se destaca el efecto terrorífico del no poder ver y del mayor horror producido por una luz insuficiente: "Ella iba temblando, con el auxilio de un farol, cuya luz escasa y pavorosa apenas despejaba un corto recinto de tinieblas" (VI, pág. 260). Porque gran parte del espanto procede de la imposibilidad de orientarse en la "oscuridad profunda" de la cárcel y en su perversa complicación arquitectónica: tienen que guiar a Sabina" por entre las tortuosas y tenebrosas sendas de aquel inextricable laberinto" (VI, pág. 264). Aun cuando espere encontrarse con su marido, cada vez que acude las sensaciones opresivas se repiten: le era "imposible acostumbrarse al horror de la cárcel: los cabellos otra vez se le erizan y el corazón le palpita en el pecho" (VI, pág. 263).

Por otra parte, la última desgracia de Sabina en la cárcel da lugar a una correspondiente puesta en escena. Cuando, en medio de las tinieblas y el silencio forzoso, Sabina piensa que, por favor especial, está con su marido, descubre que su infame perseguidor lo ha suplantado, pasando entonces "del

30. La cárcel constituye uno de los lugares típicos de lo terrorífico arquitectónico en las obras góticas. Parece ser que es en el XVIII cuando, fomentado por la preocupación humanitaria ante la dureza de los castigos anteriores, a la vez que comienzan a disminuirse en la realidad precisamente -como es lógico, por una mayor sensibilidad hacia ellos- es cuando alcanzan mayor amplitud en la imaginación, en la expresión gráfica o literaria (Glendinning, 1994; Romero Tobar, 1994). 
más alto grado de la dicha al colmo del espanto, de la sorpresa y el horror" (265):

Se arranca con violencia de tan pérfidos brazos [...]. La infeliz engañada no puede contener la violencia de su dolor, y da gritos horribles y espantosos que resuenan en las bóvedas del vasto subterráneo [...]. El pérfido robador de su honra, el sacrílego profanador de su virtud, aunque cortesano y aguerrido, se intimida y tiembla, teme los primeros furores de cólera tan justa, se acobarda y confunde, viendo que la violada Sabina intenta quitarse la vida, que golpea su cabeza contra la pared, que se despedaza las carnes y se arranca los cabellos (VI, pp. 265-267).

Cuando al fin se ilumina el recinto, el comentario del narrador describe la escena que sucede a la desesperación de Sabina y que, ahora, puede verse:

¡Qué espectáculo alumbra aquella luz! Una mujer ensangrentada, con las heridas de su propio dolor, que, vergonzosa, se cubría el rostro con las manos y que rechazaba con el gesto y la voz al delincuente poderoso que tenía a sus pies (VI, pág. 267).

Otro tipo de lugar terrorífico, paisaje exótico de sabor extraño, es el que se presenta al final de La hermosa malagueña. En esta novela, la violencia se debe a Selín, aunque la cuestión de fondo sólo es un equívoco. Los que contemplan ocultos su furia, aunque el traidor Clandol con razón teme, se engañan en aspectos esenciales. Pero lo que interesa aquí es el efecto de todo ello en los lugares en que ocurre. En este caso, el momento de mayor terror se da en un sitio concreto: al comienzo, en una cueva -un espacio reducido, inseguro, particularmente amenazador; después en campo abierto, pero espantoso por otros motivos. En un momento dado, los fugitivos huyen de noche; a la luz de la luna ven una cueva donde se refugian; por encima pasan los caballos de los perseguidores y oyen las órdenes espantosas de Selín. Permanecen aterrados, tendidos en el húmedo suelo de la cueva:

Clandol, más turbado y más temeroso todavía, apenas se atrevía a respirar. Sólo se oía el crujido de sus dientes, que con movimientos convulsivos chocaban trémulos los unos con los otros, y todos hubieran querido que el corto espacio en que yacían ocultos se hubiera aniquilado (IV, pp. 79-80).

Florencia piensa que Selín ha decapitado a su marido; sólo quiere entonces volver a la llanura ensangrentada, con muestras - que se identifican-de perturbación mental:

Allí vio las huellas recientes del delito, y se estremece. Se arroja al suelo, besa esta tierra preciosa y la inunda con su abundante llanto. Luego repara en las manchas de sangre, que enrojecía el verdor de las plantas. Esta vista le horroriza, y, trémula, se arrastra por el sendero que la muestra. La besa con su boca y quiere que Clandol la deje morir en aquel sitio [...]. La muerte me gusta, yo la amo, yo la invoco, pues mi marido está en ella [...]. Diciendo esto aplicaba su rostro contra el terreno humedecido con la sangre, cubría la tierra con su boca, y parecía que quería sofocar allí los últimos alientos que debían salirle de los labios (IV, pp. 84-86). 
Con muy buen acuerdo, "Clandol sintió que su cabeza estaba trastornada, que sería inútil toda resistencia, y ocioso hablarle el lenguaje de la razón" (IV, pág. 86). La protagonista llora, desesperadamente; y el paisaje que contempla es no poco misterioso, elemento de terror más cercano a los escenarios góticos -aunque en campo abierto- de lo habitual en las Lecturas, incluso en las sombrías:

Pero, ¡vana esperanza!, su vista no alcanza a ver en esta isla tan anhelada más que una vasta y horrible soledad. El eco de las ásperas rocas no repetía más que sus gemidos, y las plantas salvajes recibían el riego de su llanto (IV, pág. 74).

\section{MUERTES VIOLENTAS, SANGRE Y DETALLES MACABROS}

La complacencia en la descripción de detalles macabros, sangre y muertes violentas, es otro de los elementos importantes del género que tienen notable desarrollo en las Lecturas útiles y entretenidas. Se encuentran en novelas muy diversas. En algún caso, dentro de lo que conocemos, ya era así en los originales franceses, lo que confirma su extensión en la época. Unas veces corresponden a los efectos de la ira cegada por la pasión, otras proceden de desgracias naturales. $\mathrm{El}$ sufrimiento moral intenso produce cambios en el aspecto físico y la conducta de los afectados, que son de por sí terroríficos; de hecho, producen horror en quienes los contemplan. Aún así, Olavide resulta sobrio y, desde luego, sin los refinamientos de crueldad que se dan, por ejemplo, en obras anteriores, como en las españolas de María de Zayas. La violencia y sus consecuencias aparecen en muchas de las novelas de las Lecturas, aunque en algunas no tienen mayor alcance, si las consideramos en su época. En otras, la referencia a estos aspectos entra plenamente en este apartado. En La satisfacción generosa, es un padre tirano el que da a su hija, falsamente culpada, una paliza inhumana que la deja irreconocible, sin que falte la referencia a las manchas físicas de sangre que materializan su brutalidad:

Pero sus pies y sus manos hacían el oficio, y su ciega saña descargaba sobre la pobre Isabel golpes terribles, que alteraban las gracias y proporciones de sus miembros delicados; sobre todo, su furor se esforzaba a estrecharla su hermoso cuello para ahogarla con sus propias manos [...]. Cuanto más procuraban contenerle, tanto más descarga su violencia contra la pobre víctima, que tendida a sus pies y despojo de su cólera, no hacía más que mancharle las manos con la sangre que derramaba (IV, pp. 199-200 y 201).

En La feliz desgracia, la cuestión es distinta. En este caso, es un accidente - una caída de caballo- lo que deja irreconocible al joven atrevido que pretende casarse con la hija de familia, con la razonable desaprobación del padre. En su terrible descripción hay una intención moralizadora que, desde luego, era imposible que la protagonista dejara de aprovechar:

Poco después llega el cirujano [...]. Lo primero que dijo fue que tenía quebrado un brazo por dos partes; luego que el muslo, la pierna y el pie del lado que había oprimido el caballo estaban en astillas; después que le halla contusiones por todo el 
cuerpo; un ojo fuera de su órbita, que le estaba colgando; las narices hechas pedazos; los labios rotos; en una palabra, toda la cara desollada. En efecto, era imposible ver figura más horrible y espantosa: parecía un monstruo que inspiraba terror, y al mismo tiempo daba asco (IX, pp. 241-242).

Más adelante se nos cuenta la reacción de la joven, "atónita y aturdida", al verlo:

Clara echa una ojeada [... ] y en lugar de aquel cuerpo hermoso que deleitó tantas veces sus ojos no ve más que un tronco sin forma humana, y mutilado por muchas partes: una cara espantosa, una cabeza hinchada y monstruosa, que no podía verse sin horror [...]. Con silencio pavoroso y con ademán despavorido contempla un momento este monstruo de miseria [...] y, no pudiendo resistir a espectáculo tan horroroso, cae de repente por tierra sin sentido (IX, pp. 249-250).

Su muerte, una de las abundantes -violentas o especialmente desgraciadas-que aparecen en Las Lecturas, es precedida de una dolorosa agonía, que se describe con fuerte rasgos:

[Vivía] pero, ¿qué vida era la suya? Ya ardía en una fiebre aguda que devoraba sus entrañas; y si empezó a dar algún indicio de sensibilidad, no fue más que para quejarse, y dar gritos espantosos que inspiraban terror. Tres días pasó en horribles delirios [...]. Las [palabras] que le salían de sus labios eran horribles y funestas. Todas eran expresiones las más lúgubres; se veía que nacían de un cerebro turbado, a quien no se presentaban más que ideas terribles que se exprimían con el acento del despecho (IX, pág. 251).

El dolor moral extremo que trastorna la mente y el aspecto físico aparece en alguna de las novelas. Quizá el más característico sea el caso de Albano, que en El fruto de la ambición, cuando se le niega su prometida, en su dolor se trastorna y acaba por morir violentamente. Antes, en un arranque de furor, decide despeñarse con su amada Rufina. Se detiene, en un momento de lucidez, cuando ya había tomado vuelo para precipitarse al abismo:

Levanta la cabeza y la mira a su lado derritiéndose en llanto. Los ojos del infeliz estaban fuera de sus quicios. Los músculos de su semblante en un estado tan convulsivo que no parecían los mismos ni era fácil reconocerlos. Todos sus miembros temblaban (V, pág. 281).

En realidad, esos sufrimientos internos llegan a producir una real transformación física en los que los padecen, hasta volverlos irreconocibles. Es parte del extravío de la razón que producen:

El amable Albano no parecía el mismo. Los cabellos se le habían erizado en la cabeza. Una palidez lívida y macilenta cubría su semblante cárdeno y descarnado: parecía la imagen de la muerte o un espectro escapado del sepulcro [... ]. La idea de que va a perderla para siempre vuelve a enajenarle la razón, irrita otra vez su furor y se siente impelido por sus angustias implacables a dar fin a los dos con un delito (V, pp. 183-184). 
Como conclusión, en este resumen, en que faltan los otros grandes campos de elementos góticos en la expresión verbal y no verbal que no era posible esbozar aquí, pensamos que lo expuesto es suficiente como panorama de algunos aspectos de la sensibilidad desgraciada extrema, de tipo gótico, que aparece en las novelas de las Lecturas. Con ello queríamos poner de relieve la importancia que le dio Olavide, al incluir en su colección aquellas tendencias que, hacia lo gótico propiamente dicho o con elementos de lo mismo, se estaban dando en la literatura de su tiempo, y que consideró de interés difundir entre los lectores de España. Sobre todo por lo que esto implica de presencia en España de las corrientes literarias contemporáneas europeas, en concreto, de esa vertiente de sensibilidad infeliz y aspectos góticos de cuya existencia en España son parte muy importante las aportaciones de las Lecturas útiles y entretenidas ${ }^{31}$.

\section{BIBLIOGRAFÍA}

AGUILAR PIÑAL, Francisco. 1981 y ss.. Bibliografía de Autores Españoles del Siglo XVIII, Madrid, Consejo Superior de Investigaciones Científicas.

ALONSO SEOANE, María José. 1984. "La obra narrativa de Pablo de Olavide: nuevo planteamiento para su estudio", Axerquia, 11, pp. 11-49.

- 1985. "Los autores de tres novelas de Olavide", en AA.VV., IV Jornadas de Andalucía y América, II, Sevilla, Escuela de Estudios Hispanoamericanos, pp. 1-22.

- 1986. "Algunos aspectos de las ideas de Olavide en las Lecturas útiles y entretenidas", Alfinge, 4, pp. 215-228.

— 1987. "Traducción y adaptación en el siglo XVIII español: una versión desconocida de la novela de Blanchard, Félix et Pauline ou le tombeau au pied du Mont-Jura", en Juan Paredes Núñez y Andrés Soria Olmedo (eds.), VI Simposio de la Sociedad Española de Literatura General y Comparada, Granada, Universidad, pp. 231-237.

— 1988 a. "Una adaptación española de Blanchard: El sepulcro en el monte de Vicente Rodríguez de Arellano", Crisol, 8, pp. 5-19.

31. En prensa este artículo, he podido localizar el manuscrito de una novela inédita de Olavide, La maldición paterna, no incluida en las Lecturas átiles y entretenidas, de la que sólo se conocía el título, y un fragmento del comienzo (las dos primeras hojas). En ella aparecen abundantes notas que la acercan a lo gótico; lo que no es de extrañar, pues asimismo, he podido identificar el original: Amne Bell, de la serie Épreuves du sentiment de Baculard d'Arnaud, en la que Olavide introduce amplias e interesantes variaciones. Recientemente, el profesor Guillermo Carnero ha desvelado un importante caso de adaptación de la misma novela: la obra dramática de Zavala y Zamora, Las víctimas del amor, Ana y Sindham (Carnero 1994). La versión de Olavide, independiente, presenta diferencias notables. Espero publicar en breve el estudio y el texto del manuscrito de Olavide.

Este trabajo forma parte del Proyecto de Investigación "La obra narrativa de Pablo de Olavide" (PS90-0034), financiado por la Dirección General de Investigación Científica y Técnica (DGICYT). 
- 1988 b. "Dos principios ilustrados en las últimas obras literarias de Olavide", en AA.VV., Carlos III y las Nuevas Poblaciones, Córdoba, Universidad de Córdoba/ Seminario de Estudios Carolinenses/Junta de Andalucía, pp. 281-298.

- 1991. "Adaptaciones narrativas en el siglo XVIII español: El amor desinteresado de Pablo de Olavide", en Ma Luisa Donarre y Francisco LaFarga (eds.), Traducción y adaptación cultural: España-Francia, Oviedo, Universidad, pp. 199-209.

- 1992. "Olavide, adaptador de novelas: una versión desconocida de Germeuil, de Baculard d'Arnaud", en Antonio Vilanova (Ed.), Actas del X Congreso de la Asociación Internacional de Hispanistas, II, Barcelona, PPU, pp. 1157-1166.

- 1993. Introducción, en Francisco MARTínez de la Rosa, La conjuración de Venecia, Año de 1310, Madrid, Cátedra.

- 1994. "Teatro y novela en el último período de la Ilustración", Actas del Congreso Internacional Teatro español del siglo XVIII, Universidad de Lleida, Octubre de 1994. En prensa.

ÁLVAREZ BARRIENTOS, Joaquín. 1991. La Novela del Siglo XVIII, Madrid-Gijón, Júcar.

ARREDONDO, María Soledad. 1989 a. "Notas sobre la traducción en el Siglo de Oro: Bandello francoespañol", en Francisco LAFarga (ed.), Imágenes de Francia en las Letras Hispánicas, Barcelona, PPU, pp. 217-227.

- 1989 b. "Erotismo trágico en el siglo XVI", en AA. VV., Eros literario, Madrid, Universidad Complutense, pp. 89-99.

CALDERA, Ermanno. 1991. "Il teatro del pathos e dell'orrore al principio dell'ottocento: fedeltà ai canoni del classicismo e presentimente romantici", Entresiglos, I, pp. 57-75.

CARNERO, Guillermo. 1983. La cara oscura del Siglo de las Luces, Madrid, CátedraFundación Juan March.

- 1985. Ed. de Fray Vicente Martínez Colomer, El Valdemaro [1792], Alicante, Excma. Diputación.

- 1993. "La holandesa de Gaspar Zavala y Zamora y la literatura gótica del XVIII español", en José Romera Castillo, Ana Freire López y Antonio Lorente Medina (coords.), Homenaje al profesor José Fradejas Lebrero, II, Madrid, Universidad Nacional de Educación a Distancia, pp. 517-539.

- 1994. "Una Tragedia burguesa con música en el teatro español de fines del siglo XVIII: Las víctimas del amor de Gaspar Zavala y Zamora", Revista de Literatura, LVI, 111, pp. 39-72.

C[ARNERERO], M[ariano]. 1805. [Crítica a Oderay], Memorial Literario, XIII, 10-V-1805, pp. 166-175.

DEMERSON, Paula de. 1976. Esbozo de biblioteca de la juventud ilustrada (1740-1808), Oviedo, Universidad.

DOWLING, John. 1984. “La sincronía en Jovellanos y Cadalso", Nueva Revista de Filología Hispánica, XXXIII, 1, pp. 218-223.

FERNÁNDEZ INSUELA, Antonio. 1992. "Sobre la narrativa española de la Edad de Oro y sus reediciones en el siglo XVIII", Revista de Literatura, 109, pp. 55-84.

FRENZEL, Elisabeth. [1976] 1980. Diccionario de motivos de la literatura universal, Madrid, Gredos.

GARCÍA GARROSA, María Jesús. 1991. "Dos nuevas versiones españolas del Décaméron François", Estudios de Investigación Franco-Española, 5, pp. 113-129. 
GIES, David T. 1988. "Larra, La Galería fúnebre y el gusto por lo gótico", en VV.AA., Atti IV Congreso sul Romanticismo Spagnolo e Ispanoamericano, Genova, Universidad, pp. $60-68$.

GLENDINNING, Nigel, 1991. "Actitudes frente al crimen y al castigo", en Siegfried JüTTNER (ed.), Spanien und Europa im Zeichen der Auklärung, Frankfurt-Bern-New York-Paris, Peter Lang, pp. 80-94.

- 1994. "Lo gótico, lo funeral y lo macabro en la cultura española y europea del siglo XVIII", Anales de Literatura Española, 10, pp. 101-115.

GODENNE, René. 1970. Histoire de la nouvelle française aux XVII et XVIII siècles, Genève, Droz.

- 1985. Études sur la nouvelle française, Genève-Paris, Editions Slatkine; a: "Les spectables d'horreur de J.P. Camus", pp. 19-29; b: "Les nouvellistes des années 17801820 et le Préromantisme", pp. 175-189.

HERRERO, Javier. 1989. "Terror y literatura; Ilustración, revolución y los orígenes de] movimiento romántico", en AA.VV. La Literatura española de la llustración: Homenaje a Carlos III, Madrid, Univ. Complutense, pp. 131-153.

LÉVY, Maurice. 1968. Le Roman "gothique" anglais, 1764-1824. Univ. de Toulouse.

MONTESINOS. José F. 1972. Introducción a una historia de la novela en España en el siglo XIX, Madrid, Castalia, $3^{\text {k ed. }}$

MOYA, Alejandro de. 1972. El café, I, Madrid, Imprenta de González.

OLAVIDE, Pablo de [Atanasio de Céspedes y Monroy]. 1800 y 1816-1817. Lecturas útiles y entretenidas, Madrid, Doblado, ts. I-VII [1800]; Dávila, vols. VIII-IX [1816], X-XI [1817].

OLIVE, Pedro María. 1796-97. Noches de invierno. Madrid, Antonio Espinosa [vols. I-V] y Viuda e Hijo de Marín [vols. VI-VIII].

PALACIOS FERNÁNDEZ, Emilio. 1993. "Guapos y bandoleros en el teatro del siglo XVIII: los temas y las formas de un género tradicional", Cuadernos de Investigación de la Literatura Hispánica, 18, pp. 253-289.

PÉREZ ZARAGOZA, Agustín. [1831] 1977. Galeria fúnebre de espectros y sombras ensangrentadas, Luis Alberto de CuENCA (ed. ), Madrid, Editora Nacional.

PICOCHE, Jean-Louis. 1985. "Les decors du drama romantique espagnol", L'homme et l'espace dans la littérature, Univ. de Lille, pp. 95-109.

ROMERO TOBAR, Leonardo. 1994. "Viajes imaginarios y cárceles de invención”, en AA.VV., Actas del IX Simposio de la Sociedad Española de Literatura General y Comparada, II, Zaragoza, Universidad, pp. 479-492.

SCHENK, Hans G. [1966] 1983. El espíritu de los románticos europeos, México, Fondo de Cultura Económica.

VINCENT-BUFFAULT, Anne. 1986. Histoire des larmes: XVIII-XIX' siècles, Paris, Rivages. 